\title{
Amniotic Band Syndrome: A Rare Oegurience
}

\section{Manik Mahajan', Poonam Sharma², Sakul Gupta ${ }^{3}$ Puneet Gupta'}

JUR

From the 'Department of Radio-diagnosis and Imaging, ASCOMS Hospital, University of Jammu, Jammu (J\&K), '2Department of Pathology, GMC Hospital, University of Jammu, Jammu (J\&K), 3 Department of Medicine, ASCOMS Hospital, University of Jammu, Jammu (J\&K), India.

\section{Abstract:}

Amniotic band syndrome is a rare set of congenital malformations attributed to the anomalous amniotic bands that entangle fetal parts during intrauterine life resulting in a broad spectrum of anatomical disturbances. It is a rare condition and is mostly associated with other musculo-skeletal disorders. Amniotic band syndrome should be considered in every newborn with congenital anomalies, especially defects of extremities and/ or body walls. We report a case of amniotic band syndrome along with $X$ ray findings in a male child born with congenital malformation of the extremities.

Key words: Amniotic Band Syndrome, Infant, Amnion, Extremities, Fetus.

\section{Introduction}

Amniotic band syndrome is a set of congenital malformations attributed to amniotic bands that entangle fetal parts during intrauterine life, which results in a broad spectrum of anatomic disturbances ranging from minor constriction rings and lymphedema of the digits to complex, bizarre multiple congenital anomalies incompatible with life [1-2]. It is a rare condition and is mostly associated with other musculo-skeletal disorders. The Amniotic band syndrome has a number of synonyms in the literature as: congenital constriction ring, annular constriction band, ADAM (amniotic, deformity, adherences, mutilations) complex, amniotic band rupture complex, Streeter dysplasia and congenital annular defect [3-5]. The prevalence in live births is
7.7:10,000 [6], 1: 70 in stillborns [7] and among abortuses as high as 178: 10000 [2]. It presents with characteristic malformations of limbs and peculiar X-ray findings. In this report we describe the clinical and $X$-ray findings in a case of Amniotic band syndrome.

\section{Case Report}

A 3 months old male child was taken by his parents to the paediatrician with chief complaints of abnormally formed left upper limb. The boy was a full term normal delivery. There was no history of trauma or drugs taken by the mother during pregnancy. Pregnancy was regularly controlled and

Corresponding Author: Dr. Manik Mahajan

Email: manikmahajan20000@gmail.com

Received: November 2, 2012 | Accepted: November 30, 2012 | Published Online: August 20, 2014 This is an Open Access article distributed under the terms of the Creative Commons Attribution License (creativecommons.org/licenses/by/3.0)

Conflict of interest: None declared | Source of funding: Nil | DOl: http://dx.doi.org/10.17659/01.2014.0077 
had a favourable course. Antenatal ultrasonography was unremarkable. At the time of birth the child cried normally and there was no cyanosis. On examination, the child was active and there was no loss of sensations and the motor tone was also normal. Examination of the left upper extremity revealed two constricting bands at the level of wrist and mid portion of the arm [Fig.1]. Examination of the lower extremity revealed clubfoot deformity in both feet [Fig.2]. No other apparent abnormality was seen. X-rays of all the limbs were advised for further evaluation. X-rays of the left upper extremity revealed two soft tissue constriction bands at the level of mid portion of humerus and wrist along with swollen limb distal to the constrictions [Fig.3]. The capitate epiphysis was also absent. $X$-ray of left foot revealed clubfoot deformity with absent middle phalangeal bone of $5^{\text {th }}$ toe [Fig.4]. Similarly X-ray of the right foot revealed clubfoot with absent distal phalangeal bones of $1^{\text {st }}, 2^{\text {nd }}, 3^{\text {rd }}$ and $4^{\text {th }}$ toes and middle phalangeal bone of $2^{\text {nd }}$ toe

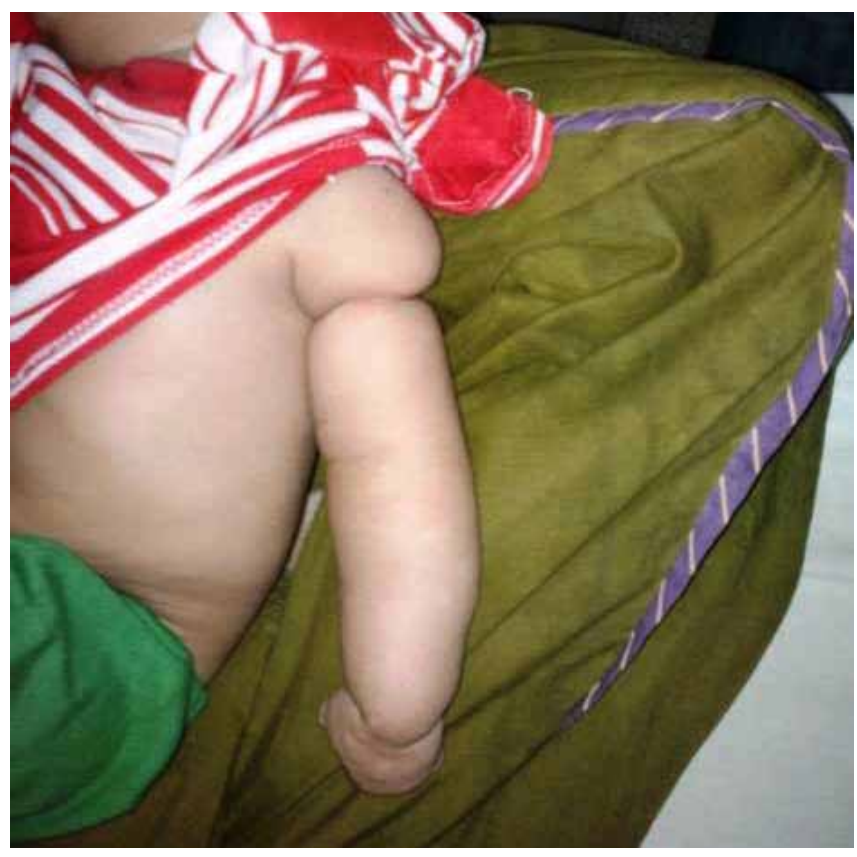

Fig.1: Left upper extremity revealing two constricting bands at the level of wrist and mid portion of the arm.
[Fig.5]. Soft tissue fusion of $1^{\text {st }}, 2^{\text {nd }}, 3^{\text {rd }}$ and $4^{\text {th }}$ toes was also seen. Based on these clinical and X-ray findings a diagnosis of amniotic band syndrome was made.

\section{Discussion}

Pathogenesis of Amniotic band syndrome is still unknown, but there are two main proposed theories [8-10]. Widely accepted "extrinsic model"

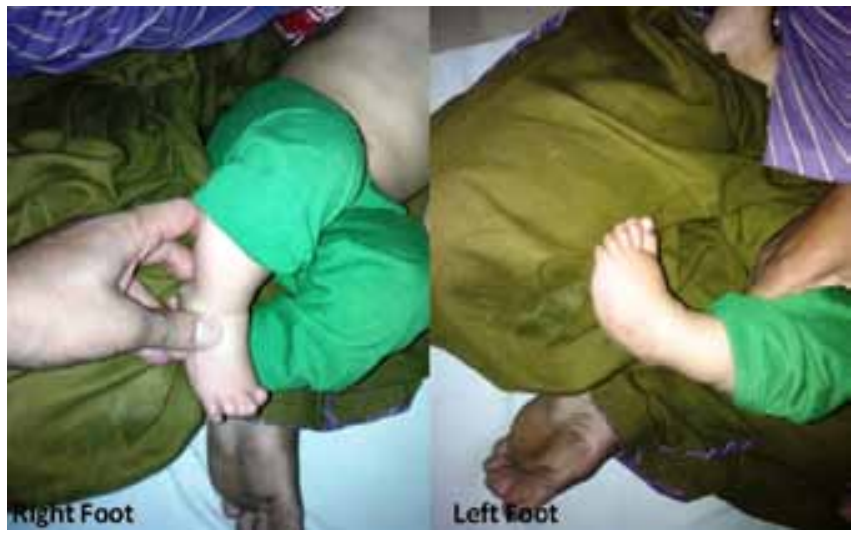

Fig.2: Clubfoot deformity is seen in both feet.

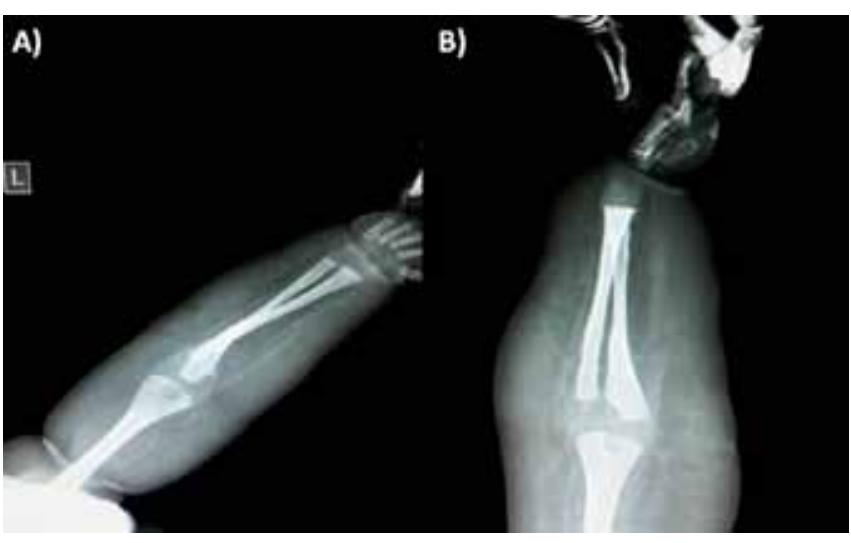

Fig.3: X-rays left upper extremity: Anteroposterior (A) and lateral (B) views showing two soft tissue constriction bands at the level of mid humerus and wrist along with swollen limb distal to the constrictions. Also note the absent capitate epiphysis which should have normally appeared by this time ( 3 months). 


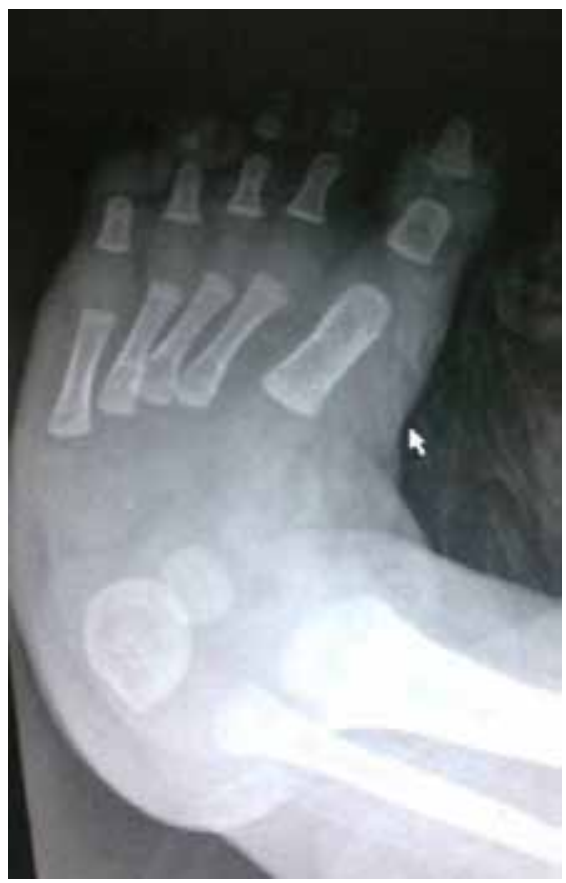

Fig.4: X-ray left foot Antero-posterior view showing clubfoot deformity with absent middle phalangeal bone of the $5^{\text {th }}$ toe.

proposed by Torpin and Faulkner in 1966 explains defects genesis by rupture of the amnion in early pregnancy, with forming of amniotic bands and amniotic liquid loss, followed by extrusion of all or parts of the fetus into the chorionic cavity. Bands entrap the parts of the growing fetus and fetal limbs. Other body parts become entangled and subjected to compression, which compromises circulation and also his growth and development with consecutive disturbances of functions and anatomy. The intrinsic model was proposed by Streeter in 1930 and suggests that the anomalies and the fibrous bands have a common origin, caused by a perturbation of developing germinal disc of the early embryo.

Risk factors which start such sequence of events, however, are also poorly known. Most cases of Amniotic band syndrome are not of genetic origin, and there is no recurrence in siblings or children of affected adults. However, there are some reports

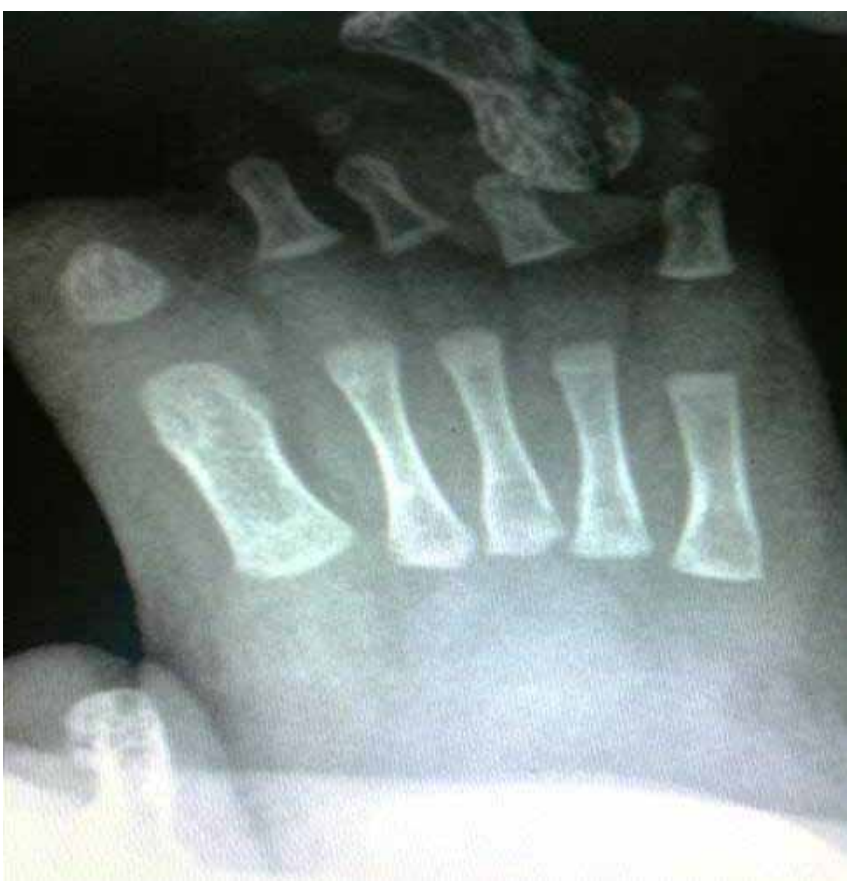

Fig.5: X-ray right foot Antero-posterior view showing absence of distal phalangeal bones of $1^{\text {st }}, 2^{\text {nd }}, 3^{\text {rd }}$ and $4^{\text {th }}$ toes and middle phalangeal bone of $2^{\text {nd }}$ toe. Soft tissue fusion of $1^{\text {st }}, 2^{\text {nd }}, 3^{\text {rd }}$ and $4^{\text {th }}$ toes is also seen.

of Amniotic band syndrome among families with collagen disorders, more specifically Ehler-Danlos syndrome $[2,11]$ and in other diseases that involve connective tissue, e.g. in osteogenesis imperfecta. Some other possible etiologic factors besides inheritance were explored in several studies. Some studies found connection between Amniotic band syndrome and mother's age especially primiparas under the age of $25[8,12]$, abdominal trauma [2,12], unsuccessful abortion, intrauterine contraception [2], amniocentesis [2], malformations of the uterus [12], some drugs like ergotamine and misoprostol [13]. However, there is no firm evidence of definite causality for any of these factors, and therefore a great number of authors consider Amniotic band syndrome as defects with sporadic occurrence, with no gender prevalence, and no strong risk factors. 
Amniotic band syndrome has very polymorphic clinical findings, because type of deformities depends on the time of amniotic rupture during pregnancy and part of the fetal body which is entangled in amniotic bands. Early amniotic rupture, during first 45 days, leads to the most severe craniofacial and visceral malformations [14]. Every part of the fetal body can be damaged, but most often extremities, especially upper extremities. Most often there are minor defects, such as constriction rings or digit amputations; but, even minor defects are multiple in $77 \%$ of cases. Abnormalities of the extremities can be expressed in several ways: constriction rings of the soft tissue accompanied by distal edema, shortening of the limb or intrauterine limb amputation, amputation of the digits (most often II, III and IV finger) and toes, syndactyly, hypoplasia of the digits, foot deformities and peripheral nerve palsies [1]. If bands compress the fetal head or face, different cranio-facial disturbances appear asymmetric face clefts, orbital defects (anopthalmos, microphtalmos, enopthalmos), corneal abnormalities, central nervous system malformations (anencephaly, encephalocoele, asymmetric meningocoele), calvaria defect. Amniotic bands can also cause abdominal wall defect and abdominal organs extrophy [1], chest wall defect with heart exstrophy [11], umbilical cord strangulation with often lethal outcome [1]. Amniotic rupture and consecutive oligohydramnios can, by mechanical pressure on the fetus, cause deformities such as metatarsovarus, scoliosis or hip dislocation [1]. Because of such a wide spectrum of possible anomalies and many combinations of their simultaneous appearance, there are no two identical cases of Amniotic band syndrome [1].

Amniotic band syndrome can be diagnosed prenatally by ultrasound, which can sometimes show amniotic bands, but more often malformations consistent with it. It can be diagnosed as early as 12 gestational weeks [16]; in the second trimester of gestation most of Amniotic band syndrome defects could be seen during routine ultrasound examinations [15]. The most important ultrasound diagnostic criteria are visible amniotic bands, constriction rings on extremities and irregular amputations of fingers and/or toes with terminal syndactyly. Mild defects, however, are less likely to be diagnosed prenatally, in which case defects are seen after birth [16]. Physical examination is the main way of postnatal diagnosis of Amniotic band syndrome, with usage of additional investigations like X-rays and echocardiography for establishing potential malformations of different organs and body parts.

Amniotic band syndrome must be considered in differential diagnosis of all complex or asymmetric malformations, especially those on extremities, face and body walls. Amniotic band syndrome should be differentiated from the whole spectra of symmetric fusion defects of middle body line $[17,18]$. In differential diagnosis some rare findings, such as amniotic folds, complex extremity-body wall, and extra-amniotic pregnancy should be taken into consideration [2].

Treatment modality for Amniotic band syndrome is mostly surgical, with an individual approach to every single case. Interdisciplinary consulting and work is very often needed (plastic surgeon, orthopaedic surgeon, orthodontist, ophthalmologist and neurosurgeon) [1].

\section{Conclusion}

Amniotic band syndrome should be considered in every newborn with congenital anomalies, especially defect of extremities and/or body walls. The basis for postnatal diagnosis is physical examination of the newborn, with additional examinations like X-rays and echocardiography so as to detect potential internal organs malformations in order to implicate proper treatment strategy. 


\section{References}

1. Poeuf B, Samson P, Magalon G. Amniotic band syndrome. Chir Main. 2008;27 Suppl 1:S136147.

2. Burk CJ, Aber C, Connelly EA. Ehlers-Danlos syndrome type IV: keloidal plaques of the lower extremities, amniotic band limb deformity, and a new mutation. J Am Acad Dermatol 2007;56(2 Suppl):S53-S54.

3. Kulkarni ML, Gopal PV. Amniotic band syndrome. J Indian Acad Ped. 1990;27:471-476.

4. Levy PA. Amniotic band. Pediatrics in Review 1998; 19:249.

5. Muguti $\mathrm{Gl}$. The amniotic band syndrome: singlestage correction Br J Plast Surg 1990;43(6):706708.

6. Buyse ML. Birth defects encyclopedia. Blackwell Scientific Publications, Cambridge, MA, 1990.

7. Ross MG. Pathogenesis of amniotic band syndrome. American Journal of Obstetrics and Gynecology 2007;197(2):219-220.

8. Werler MM, Louik C, Mitchell AA. Epidemiologic analysis of maternal factors and amniotic band defects. Birth Defects Res A Clin Mol Teratol 2003;67(1):68-72.

9. Fathallah ZF. Unusual Presentation of Amniotic Band Syndrome. Bas J Surg 2007; 1 1:77-79.

10. Lateo SA, Taylor AE, Meggitt SJ. Raised limb bands developing in infancy. $\mathrm{Br} J$ Dermatol 2006; 154(4):791-792.

11. Kutlu Dilek TU, Yazici G, Gulhan S, Polat A, Dilek B, Dilek S. Amniotic Band Syndrome Associated
With Cranial Defects and Ectopia Cordis: A Report of Two Cases. J Turkish German Gynecol Assoc 2005;6(4):308-310.

12. Dyer JA, Chamlin S. Acquired Raised Bands of Infancy: Association with Amniotic Bands. Pediatric Dermatology 2005;22(4):346-349.

13. McGuirk CK, Westgate MN, Holmes LB. Limb Deficiencies in Newborn Infants. Pediatrics 2001 ; 108(4):e64-e70.

14. Jabor MA, Cronin ED. Bilateral cleft lip and palate and limb deformities: a presentation of amniotic band sequence? J Craniofac Surg 2000; 11 (4):388-393.

15. Allen LM. Constriction Rings and Congenital Amputations of the Fingers and Toes in a Mild Case of Amniotic Band Syndrome. Journal of Diagnostic Medical Sonography 2007;23:280285.

16. Merrimen JL, McNeely PD, Bendor-Samuel RL, Schmidt MH, Fraser RB. Congenital placentalcerebral adhesion: an unusual case of amniotic band sequence. Case report. I Neurosurg 2006;104 (5 Suppl):352-355.

17. Bower C, Norwood F, Knowles S. Amniotic band syndrome: a population-based study in two Australian states. Paediatric and Perinatal Epidemiology 1993;7(4):395-403.

18. Narang $M$, Nidhi, Danewa A. Streeter's Dysplasia. Journal of Case Reports $2011 ; 1(1): 16-17$. 